NASA Technıcal Memorandum 85944

NASA-TM-85944 19840013763

\title{
Turbulence Structures Associated with the Bursting Event
}

John Kim

Aprıl 1984

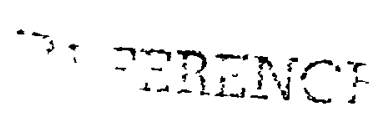

${ }^{2} E_{T}+\cdots+\cdots+\cdots$

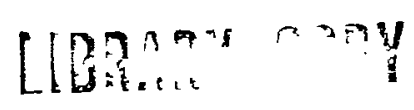

LENGLE) E=-

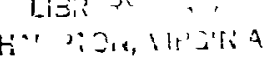




\section{Turbulence Structures Associated with the Bursting Event}

John Kım, Ames Research Center, Moffett Field, Calıfornıa

\section{N/Sก}

National Aeronautics and

Space Admınıstratıon

Ames Research Center

Moffett Field Calitornıa 94035

$N 84-21831 \#$ 
Turbulence structures associated with the bursting event

John Kim

NASA Ames Research Center, Moffett Field, California 94035

Received

ABSTRACT

Turbulence structures in a wall-bounded shear layer durıng the bursting event detected by a conditional sampling technique are investigated using data obtained from large-eddy simulation of turbulent channel flow. Streamlines are constructed from the ensemble-averaged velocity fleld to illustrate the flow patterns associated with the bursting event. They exhibit the splatting motions during the sweep event and the existence of a pair of counterrotatıng streamwise vortices during the ejection process. 


\section{INTRODUCTION}

Organized structures in turbulent flows have been a subject of much investıgation in the past two decades. Despite a great deal of effort to Identify their characteristics, the lack of consensus on the detarled description of the structures still prevalls. Comprehensive reviews on the subject are recently given by Cantwel1 $1^{1}$ and Hussain. ${ }^{2}$

In this paper, detailed flow patterns associated with the bursting event in the near-wall region of turbulent boundary layers are invest1gated. The bursting phenomenon is composed of a sequence of quasicyclic events that occur in the wall region of turbulent flows. During this event, approximately $70 \%$ of total turbulence production occurs (see Kim et $\mathrm{al.} .^{3}$ and $\mathrm{KlIne} \mathrm{H}^{4}$ ); hence, this is regarded as one of the most important processes in wall-bounded turbulent shear flows. An understanding of this phenomenon is essential to a better insight into the dynamics of the turbulent transport process. Because of its importance, the bursting phenomenon has attracted a great deal of theoretical and experimental interest. Nevertheless, the exact description of this event, as well as its cause, is still in question. $\mathrm{Kllne}^{4}$ and Brodkey provide excellent perspective views based on their pioneering work accumulated in over a decade at Stanford and Ohio State universities, respectively. Recently, Smith ${ }^{6}$ proposed a synthesized model derıved from his flow-visualization work. Most of the previous work, however, fails to provide a clear picture of flow patterns associated with the bursting event because of the difficulty involved in obtaining the necessary information experimentally. Hussain ${ }^{2}$ summed up the difficulty 
as follows: "Flow visualization presents excessive information but very little hard data, and anemometer data give some hard data but very limited flow physics." Recently, with the advent of large and fast computers, computer simulations of turbulent flows have shown that these simulations can be used as alternative research tools (see Rogallo, ${ }^{7}$ Moln and Kim, ${ }^{8} \mathrm{KIm},{ }^{9}$ and Moin, ${ }^{10}$ for example). From these tımedependent three-dimensional simulations, one can obtain any desired information on the instantaneous three-dimensional velocity and pressure field.

The study reported here is a continuation of the author's previous work, ${ }^{9}$ In which the conditional sampling technique developed by Blackwelder and Kaplan ${ }^{11}$ was applied to computer-generated data obtained from a large-eddy simulation of turbulent channel flow. ${ }^{8}$ Varıous ensemble-averaged quantitıes, such as velocity, pressure, and vorticity, were discussed in conjunction with the bursting phenomena detected by the conditional sampling technique. In the present work, more detalled flow patterns are described in terms with streamlines and contours constructed from the three-dimensional ensemble-averaged velocity field.

In the aforementioned work of Moin and $\mathrm{Kim}^{8}$ a fully developed turbulent channel flow was simulated numerically at a Reynolds number of 13,800 , based on the centerline velocity and the channel half-width. The large-scale flow field was obtained by integrating the filtered, three-dimensional Navier-Stokes equations. The small-scale field motions were simulated through an eddy-viscosity model. The calculations were carrled out with 516,096 grid points. The grid spacings in the 
streamwise and spanwise directions were $\Delta x \approx 62$ and $\Delta z \approx 15$ in wall units. Nonuniform meshes were used in the normal direction, and the first mesh point away from the wall was $y^{+}=1.78$. The results were verified by comparing the statistical properties of the computed flow field with experimental results of turbulent channel flows. In addition, the turbulence structures in the vicinity of the wal1-of-the-channe1 flow were found to be the same as the structures in the wall region of turbulent boundary layers. These data base obtained from the channel simulation were used in $\mathrm{Kim}^{9}$ and the present work to study the flow structure associated with the bursting event in the near-wal1 region of turbulent boundary layers.

\section{CONDITIONAL SAMPLING}

To obtain an ensemble-averaged flow structure of the bursting event, the variable-interval time-averaging (VITA) technique developed by Blackwelder and Kaplan ${ }^{11}$ is chosen as the conditional sampling process. In the present study (as in $\mathrm{Kim}^{9}$ ), however, the conditiona1averaging process is slightly modified to obtain a spatial structure rather than the temporal structure as in Blackwelder and Kaplan; the structures can be approximately related to each other by using Taylor's hypothesis. It should be noted that most of the quantitative measurements in a laboratory experiment produce temporal structures, whereas most flow-visualization experıments generally yield spatial structures. A summary of the conditional sampling technique employed In the present work is given below, but the reader should refer to Blackwelder and Kaplan ${ }^{11}$ and to $\mathrm{Kim}^{9}$ for details. 
The varıable-interval space-averaging (VISA) is defined as

$$
\begin{aligned}
\hat{u}\left(x, y, z, t_{0}, L\right) & =\frac{1}{L} \int_{x-\frac{L}{2}}^{x+\frac{L}{2}} u\left(\xi, y, z, t_{0}\right) d \xi, \\
\text { var } & =\widehat{u^{2}}-\hat{u}^{2}, \\
D(x) & = \begin{cases}1, & \text { for var }>k_{r m s}^{2} \text { and } \partial u / \partial x<0 \\
0, & \text { otherwise }\end{cases}
\end{aligned}
$$

and

$$
\left\langle u\left(x, y, z, t_{0}\right)\right\rangle_{y+}=\frac{1}{N} \sum_{j=1}^{N} u\left(x+\xi_{j}, y, z, t_{0}\right),
$$

where $\mathrm{L}$ is the width of the spatial averaging. For all the data discussed in this paper, a threshold value, $k=1.2$ and $\mathrm{L}=8 \Delta \mathrm{x}$, correspondıng to 500 wall units (1.e., $\mathrm{L}^{+} \equiv \mathrm{Lu}_{\tau} / v=500$ ), were used. The detection criteria were applied at $y^{+}=21$. These procedures were applied to the data base generated by Moin and $\mathrm{K} \mathrm{m},{ }^{8}$ and the results reported in this paper were obtained by ensemble-averaging over more than 3000 independent events.

\section{TURBULENCE STRUCTURE}

To illustrate the flow patterns associated with the bursting event, streamlines are constructed from the ensemble-averaged velocity field in several different planes. Figure 1 shows streamlines in the $(x-y)$ plane at $z=0$, where $x, y, z$ correspond to the streamw1se, normal-to-the-wa11, and spanwise directıons. These streamlines are constructed in a frame of reference moving at a speed of $0.85 \mathrm{U}_{\mathrm{c}}$, 
where $U_{c}$ is the mean velocity at the centerline of the channel. This speed was chosen as an assumed convection speed of large-scale structures (the correct convection speed of the large-scale structure is not known, but the qualitative picture does not change with different convection speeds). As a reference, the ensemble-averaged streamwise velocıty at $\mathrm{y}^{+}=21$, where the detection criteria were applied $\left(\mathrm{x}^{+}=0, \mathrm{y}^{+}=21\right.$, $z^{+}=0$ ), is given at the upper half of the figure. Note that the streamwise extent of the figure is about 4000 wall units, and the vertical extent is from the wall to the centerline of the channel, which corresponds to 640 wall units. At this convected frame of reference, there exists a saddle point just upstream of the detection point exhıbiting a simflar flow pattern as in a turbulent mixing layer. ${ }^{12}$

Streamlines in the $(y-z)$ planes, which are perpendicular to the mean flow direction, are shown in Figs. 2 and 3 . The horizontal extent of these figures is about 600 wall units. Streamlines in Fig. 2 are at the upstream of the detection point, $\mathrm{x}^{+} \approx-124$, and show that high-speed fluld moves toward the wall (sweep event), thus creating an excess in the streamwise velocity, as indicated in the upper part of Fig. 1. Downstream of the detection point, $\mathrm{x}^{+} \approx 124$, Fig. 3 reveals that underneath the sweep event a pair of counterrotating streamwise vortices is formed such that between them the low-speed fluid from the wall region is pumped away from the wall (ejection event), creating a defect in the streamwise velocity. The corresponding velocity vectors are plotted in Figs. 4 and 5 . Here, the velocity vectors are drawn paralle1 to the vectors formed by the spanwise and normal component of the 
velocity. The purpose of these vector plots is to check the assumption one has to make in order to construct the streamlines in the $(y-z)$ planes - that is, $\partial u / \partial x \approx 0$. By comparing Figs. 2 and 3 with Figs. 4 and 5 , we notice no discernible difference in the flow patterns; this validates the approximation used in constructing Figs. 4 and 5 . Contours of streamise vorticity of the ensemble-averaged velocity field in $(y-z)$ planes are shown in Figs. 6 through 8 . The sense of rotation of the vorticity is such that positive vorticity (solid lines) Indicates clockwise rotation, and negative vorticity (dashed lines) Indicates counterclockwise rotation. In FIg. 6, upstream of the detection point $\mathrm{x}^{+} \approx-124$, we notice that the sweeping motion of the high-speed fluld, depicted as a pair of counterrotating vortices in the figure, induces vorticity of opposite sign near the wall owing to the no-slip boundary condition. This viscosity-induced vorticity appears to be the source of the counterrotating streamwse vortices that appear downstream of the detection point, as shown in Figs. 7 and 8 . As the streamwise vortices are moving away from the wall because of the self-Induced motion as well as because of the Imposed pressure gradient (see $\mathrm{K}^{\mathrm{m}} \mathrm{m}^{9}$ for detalls), they not only destroy the original vortices above, but also induce the opposite sign streamwise vorticlty underneath them. Note also that the cores of the streamwise vortices approach each other as they move away from the wall. In FIg. 7, the distance between the centers of the counterrotating vortices is about 120 wall units and the centers are located about 25 wall units away from the wall; they are 75 wall units apart at about 45 wall unzts away from the wall in Fig. 8. (The scaling of 
the large-scale structure was not captured properly in the simulation of Moln and $\mathrm{Kim}^{8}$ because of the numerical resolution problem; therefore, any quantitative information must be taken with some care.)

Contours of streamwise and normal velocities in the $(x-y)$ plane are shown in Figs. 9 and 10. In these figures, solid lines represent positıve values and dashed lines represent negative values. For the streamwse velocity, the mean value is subtracted from the ensembleaveraged velocity; hence, the positive and negative values are relative to the local mean value. These figures show that the high-speed flurd moving toward the wall is riding on top of the low-speed fluld in the wa11 region. Figures 11 and 12 show the contours of the streamwse velocity in the $(x-z)$ plane at $y^{+}=12$ and $(y-z)$ plane at $\mathrm{x}^{+}=186$. These figures show that the low-speed fluid is completely surrounded by the high-speed fluid except at the downstream end, and it appears that the high-speed fluid causes the low-speed flund to be squirted out. These figures are consistent with the description of Praturi and Brodkey ${ }^{13}$ that the low-speed fluld is trapped between fingers of the high-speed fluid.

Recently, Smith, ${ }^{6}$ in an attempt to 1llustrate the existence of horseshoe vortices in the near-wall region of turbulent boundary layers, demonstrated that there exists a strong similarity between the laminar flow over a hemispherıcal protuberance and a turbulent flow during the bursting events. He proposed a model, in which the horseshoe vortices are formed in the low-speed streak regions by a process simılar to that in laminar flow where the horseshoe vortices are formed when 
vortex sheets are peeled off from the hemispherical surface. There is no evidence in the present results to contradict the proposed model. In fact, one can easily visualize the low-speed region, although it is cigar-shaped rather than hemispherical, plays a similar role to that of the hemispherical protuberance in the laminar flow. This is, however, in contrast to the description above in that the low-speed fluid is considered now to be the cause of the streamwise vortices rather than a consequence of them as viewed by the present author. Obviously, more work needs to be done before definite conclusions are drawn on this cause-and-effect relationship.

IV. SUMMARY

Detailed flow patterns associated with the bursting event in turbulent flows are constructed from the ensemble-averaged velocity field obtalned by applying a conditional sampling technique to the data base generated by the large-eddy simulation of turbulent channel flow by Moln and Kım. ${ }^{8}$ Thıs is the first time such detalled flow patterns occurring during the bursting event have been obtained. In particular, during the ejection event, the streamlines and velocity vectors downstream of the detection point exhibit clearly a pair of counterrotating streamwise vortices underneath the sweeping motion. Contours of streamw1se vorticity in several streamwise locations suggest that the viscous-induced vorticity during the sweep event may be the source of the streamwise vortices. Th1s is in contrast to the model suggested by Smith, ${ }^{6}$ which conjectures that the streamwise vortices are formed by the low-speed region. Contours of the ensemble-averaged velocity 
show that the low-speed fluid in the wall region is surrounded by the high-speed fluid, which is consistent with the description of Praturi and Brodkey. 13

\section{ACKNOWLEDGMENT}

The author is grateful to $P$. Moin for numerous helpful discussions throughout the course of this work. 
REFERENCES

${ }^{1}$ B. J. Cantwe11, Ann. Rev. Fluid. Mech. 13, 457 (1981).

${ }^{2}$ A. K. M. F. Hussain, Phys. Fluids 26,2816 (1983).

${ }^{3}$ H. T. KIm, S. J. Kline, and W. C. Reynolds, J. Fluid Mech. 50, 133 (1972).

${ }^{4}$ S. J. Klıne, in Coherent Structure of Turbulent Boundary Layers, AFORSR/Lehigh University Workshop, edited by C. R. Smlth and D. E. Abbott (1978), p. 1 .

${ }^{5}$. S. Brodkey, see Ref. 4 (1978), p. 28 .

${ }^{6} \mathrm{C} . \mathrm{R}$. Smith, in Proceedings of the E1ghth Symposium on Turbulence, edited by G. K. Patterson and J. L. Zakin (University of Missour1-Rolla, 1983)

${ }^{7}$ R. S. Rogallo, NASA TM-81315 (1981).

${ }^{8}$ P. Moin and J. Kim, J. Fluid Mech. 118, 341 (1982).

${ }^{9} \mathrm{~J}$. Kım, Phys. Fluids 26, 2088 (1983).

${ }^{10}$ P. Moln, AIAA Paper 84-0174, 22nd Aerospace Sclences Meeting, Jan. 9-12, Reno, Nev. (1984).

${ }^{11}$ R. F. Blackwelder and R. E. Kaplan, J. Fluid Mech. 76, 89 (1976). 
${ }^{12}$ A. K. M. F. Hussain, IUTAM Symposium on Turbulence and Chaotic Phenomena in Fluids, September 5-10, Kyoto, Japan (1983).

${ }^{13}$ A. K. Praturi and R. S. Brodkey, J. Fluld Mech. 89, 251 (1978). 


\section{FIGURE CAPTIONS}

FIG. 1 Streamlines in the $(x-y)$ plane at $z=0$. The upper figure is the conditionally averaged streamwise velocity at $y^{+}=21$. Note that each increment in $x$ corresponds to $\Delta x^{+} \approx 62$.

FIG. 2 Streamlines in the $(y-z)$ plane upstream of the detection point, $\mathrm{x}^{+} \approx-124$. Note that each increment in $\mathrm{z}$ corresponds to $\Delta \mathrm{z}^{+} \approx 15$.

FIG. 3 Streamlines in the $(y-z)$ plane downstream of the detection point, $\mathrm{x}^{+} \approx 124$.

FIG. 4 Velocity vectors in the $(y-z)$ plane at $x^{+} z-124$.

FIG. 5 Velocity vectors in the $(y-z)$ plane at $x^{+}=124$.

FIG. 6 Contours of streamwise vorticity in the $(y-z)$ plane at $x^{+} \approx-124$.

FIG. 7 Contours of streamwise vorticity in the $(y-z)$ plane at $x^{+}=0$.

FIG. 8 Contours of streamwise vorticity in the $(y-z)$ plane at $\mathrm{x}^{+} \approx 124$.

FIG. 9 Contours of fluctuating streamwse velocity in the $(x-y)$ plane at $z=0$.

FIG. 10 Contours of normal velocity in the $(x-y)$ plane at $z=0$. 
FIG. 11 Contours of fluctuating streamise velocity in the $(x-z)$ plane at $y^{+} \approx 12$.

FIG. 12 Contours of fluctuating streamwise velocity in the $(y-z)$ plane at $x^{+} \approx 124$ 

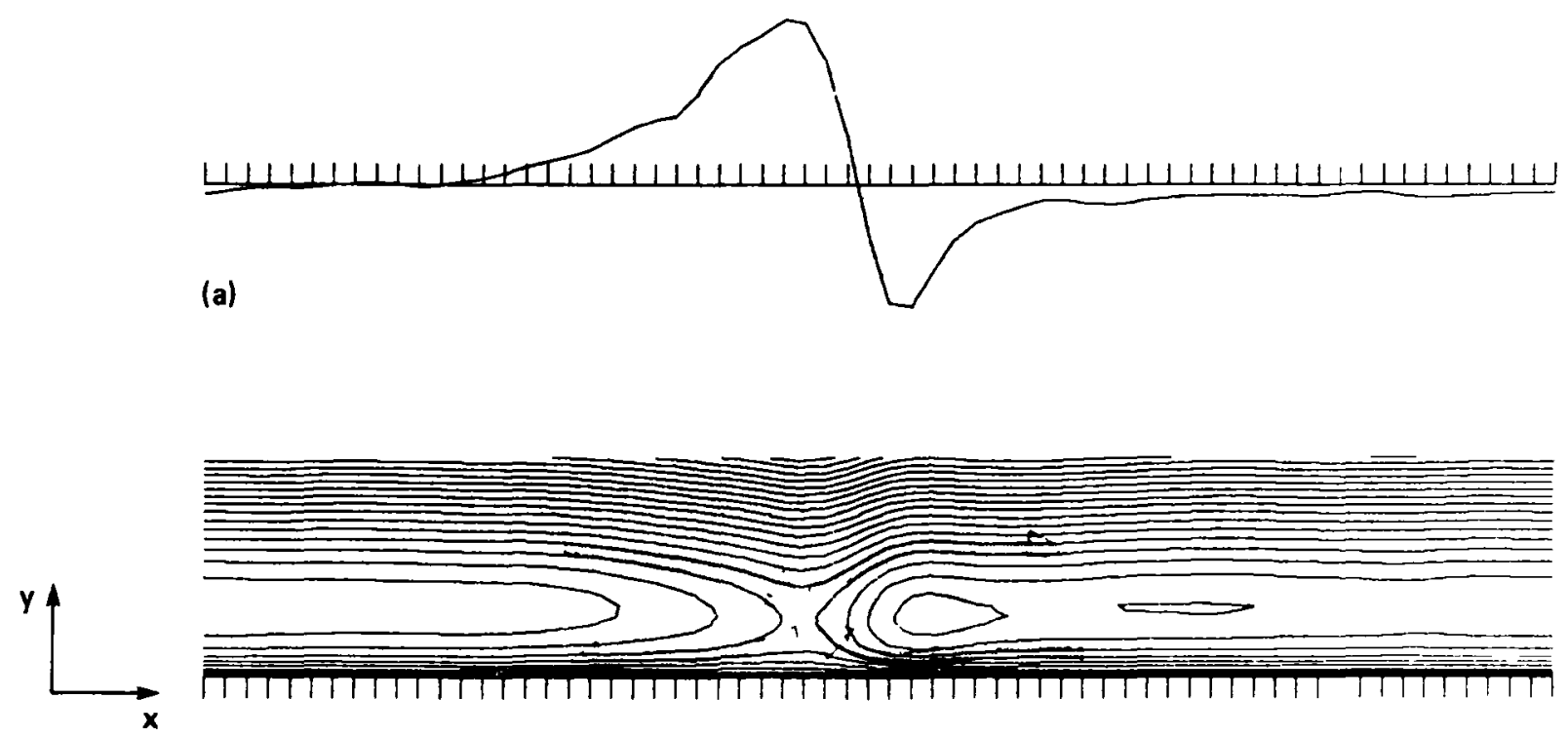

(b)

Fig. 1 


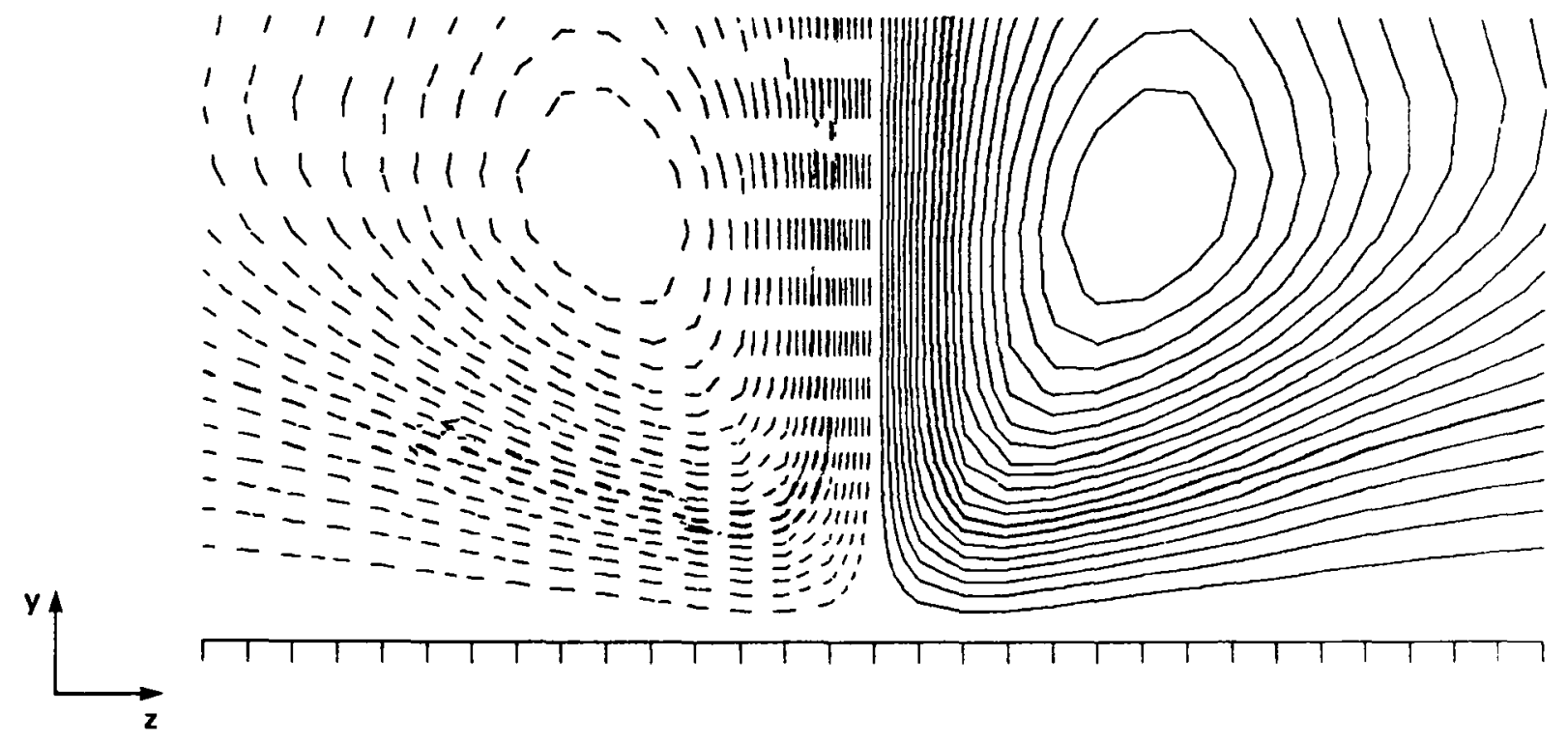

Fig. 2 


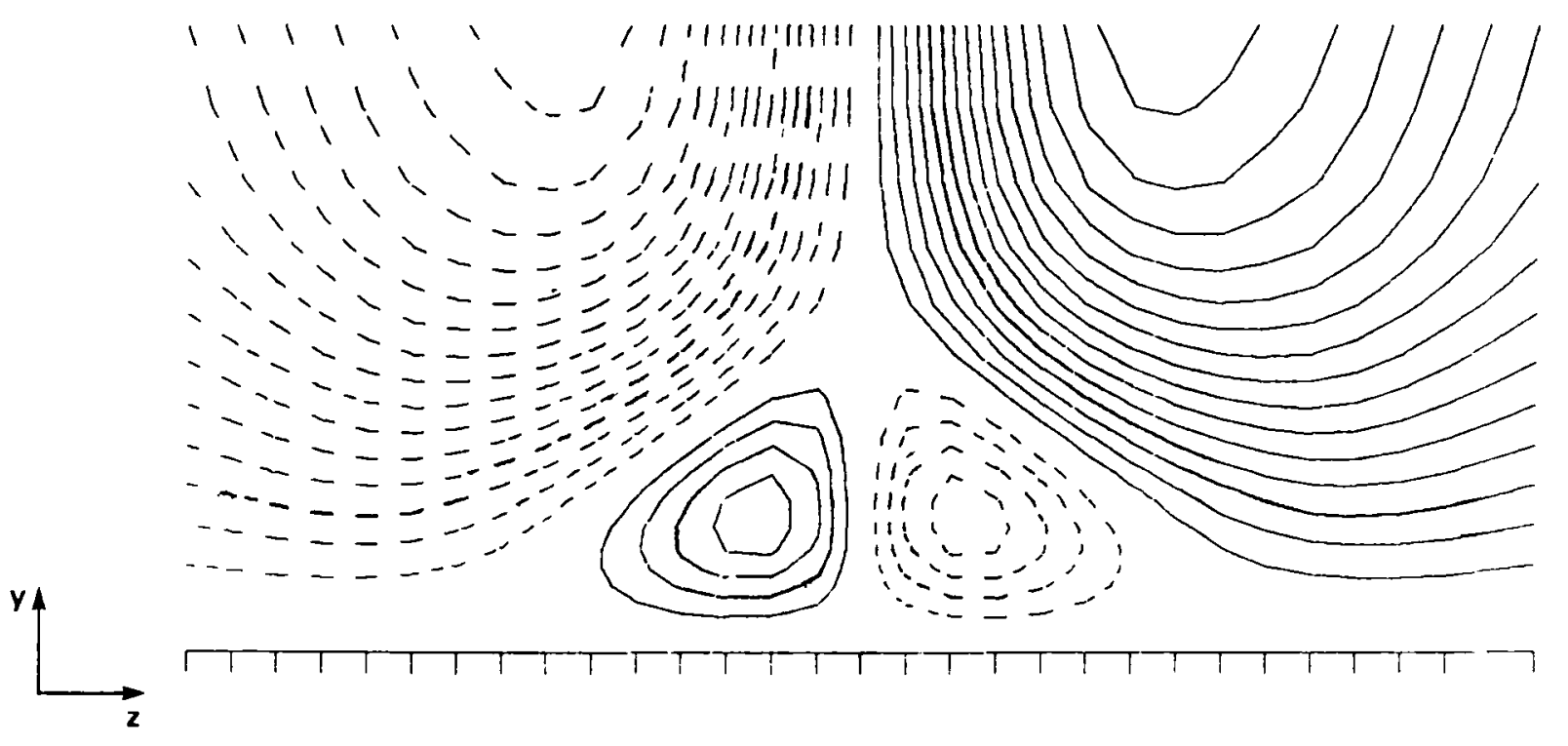

Fig. 3 


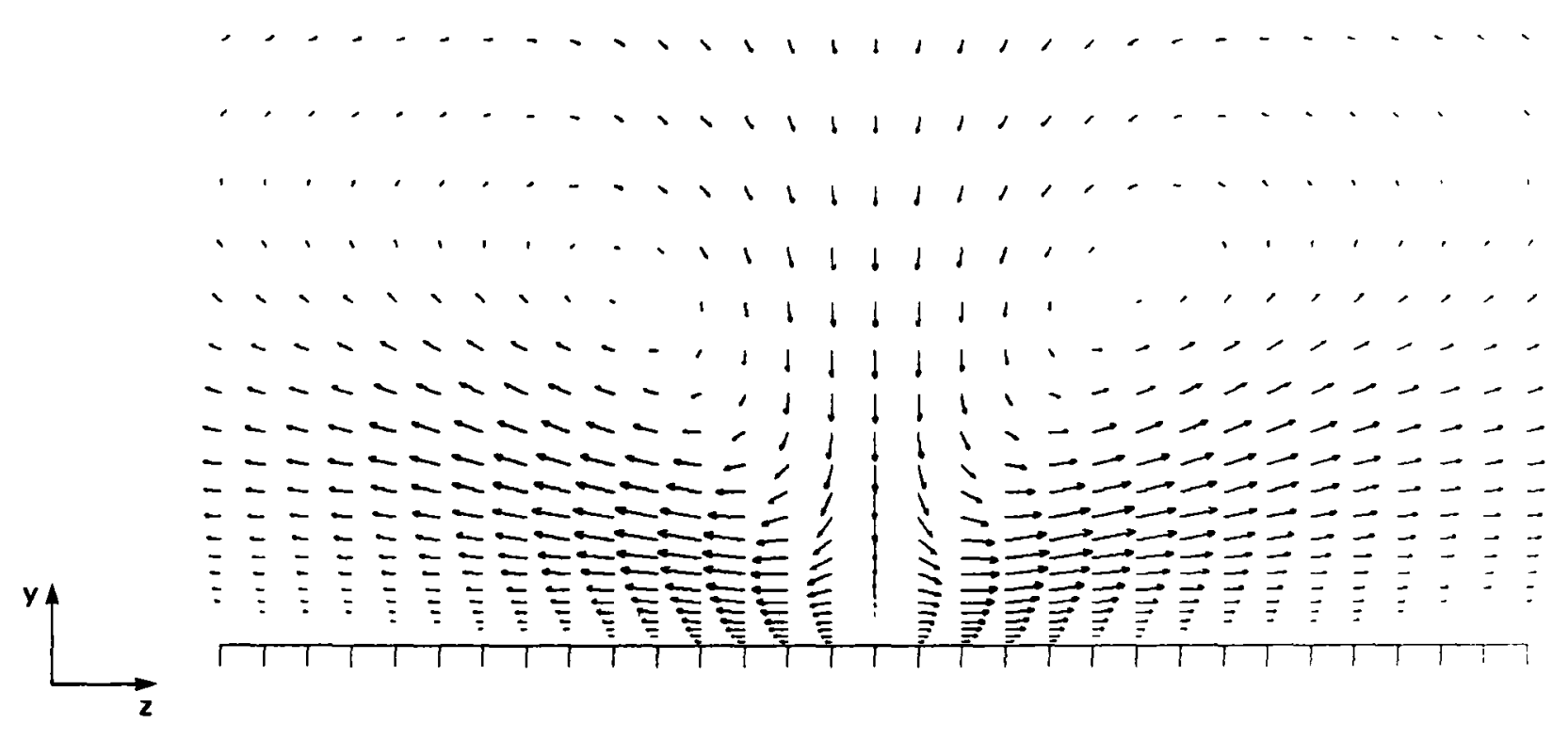

Fig. 4 


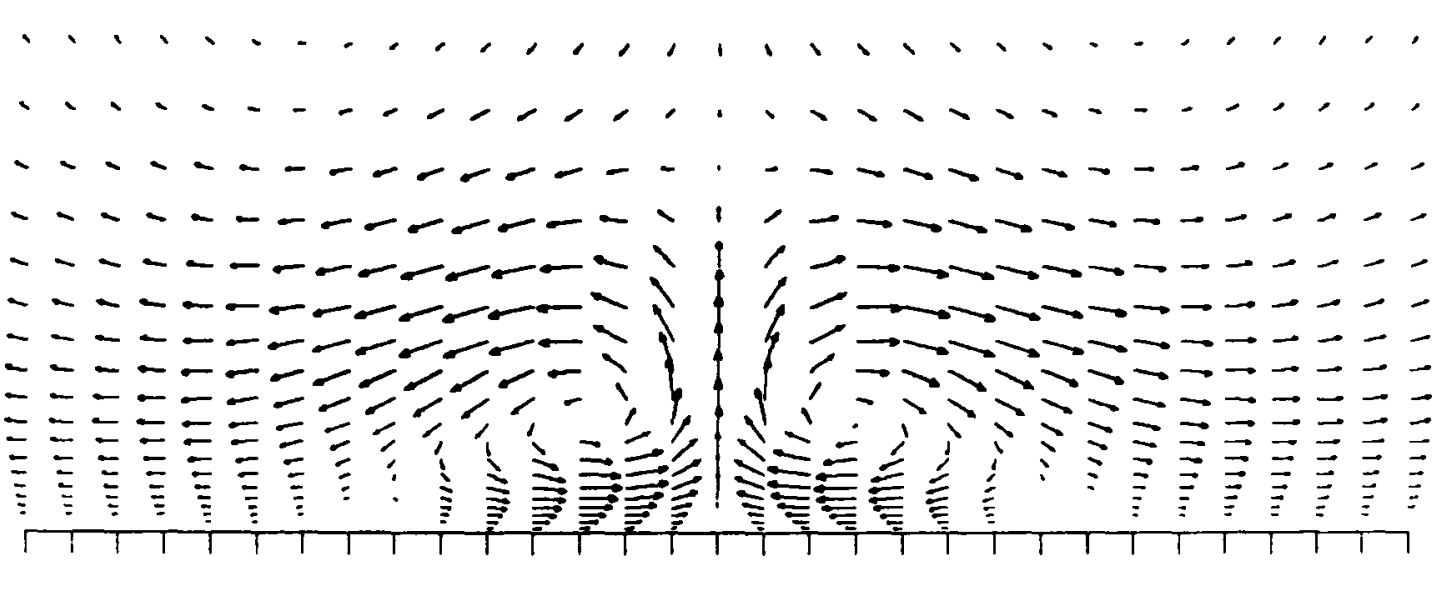

Fig. 5 


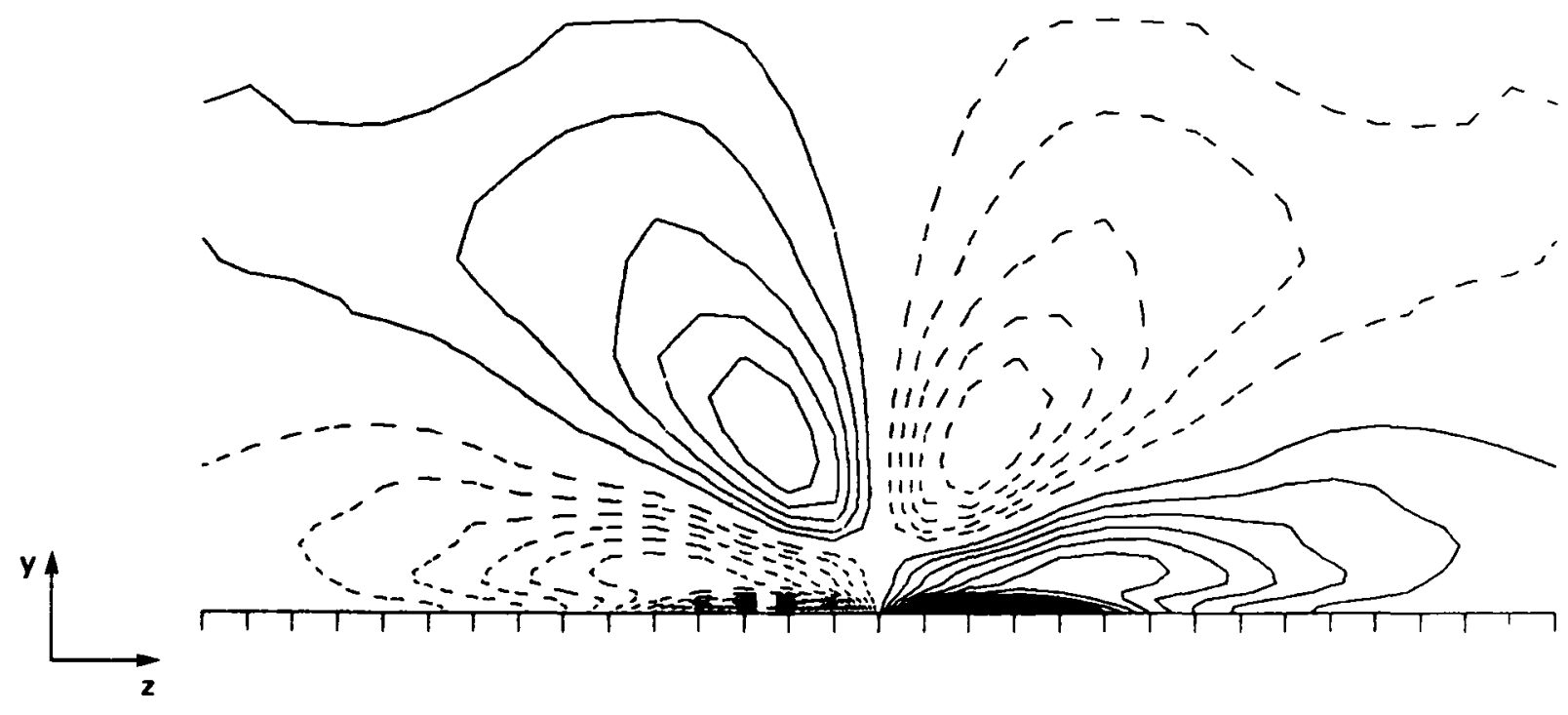

Fig. 6 


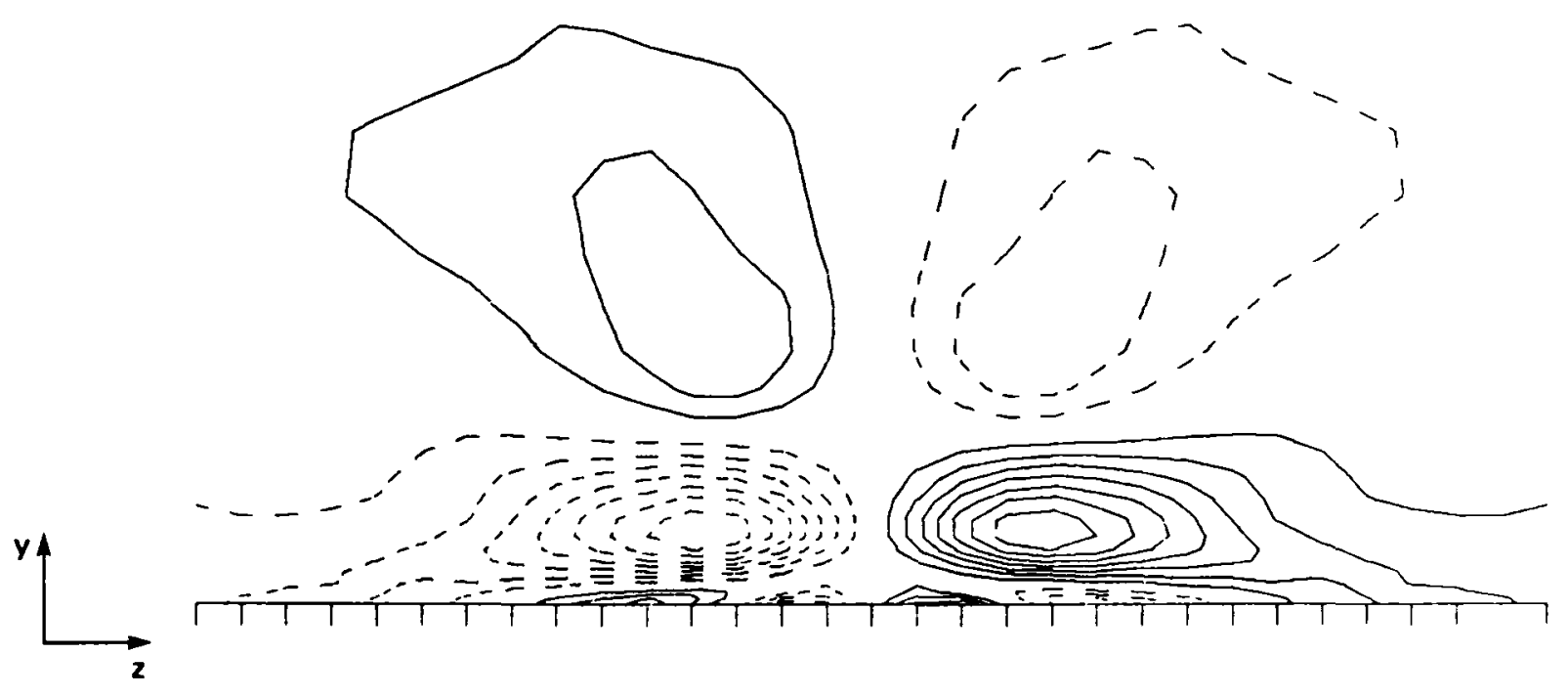

Fig. 7 


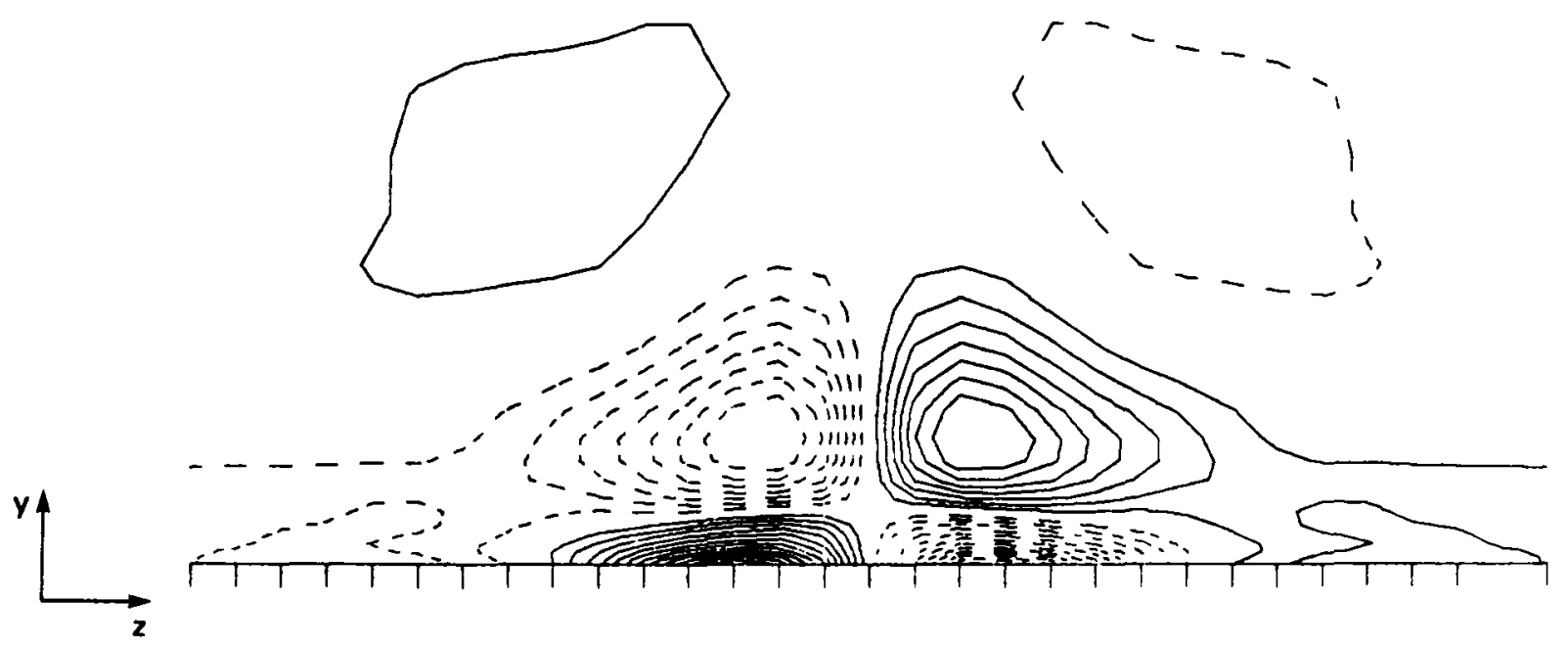

Fig. 8 


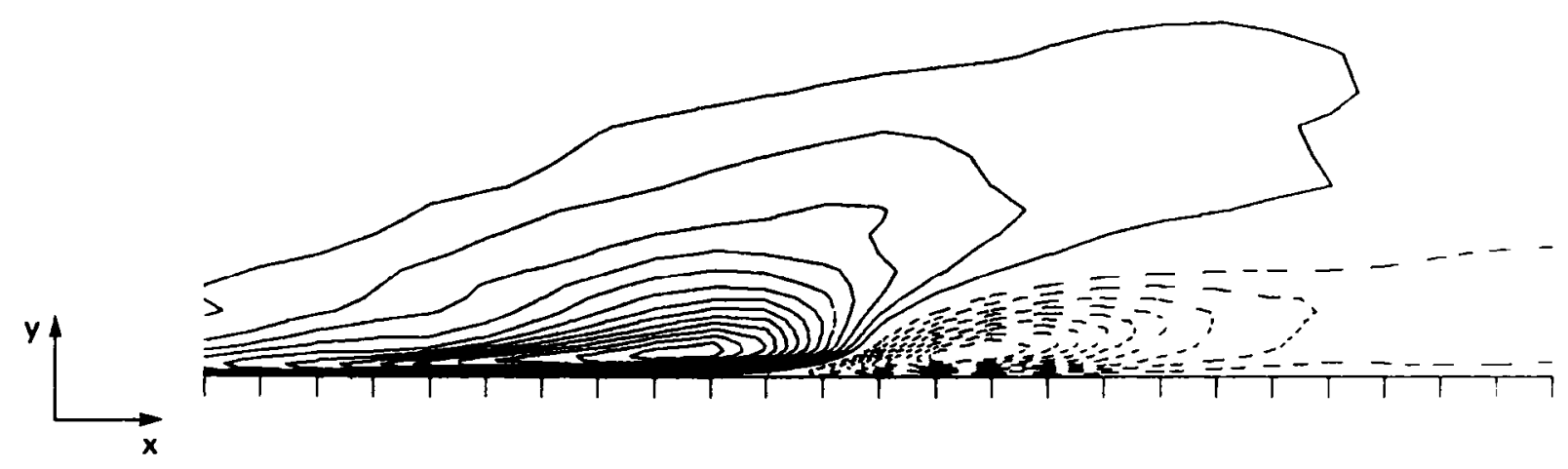

Fig. 9 


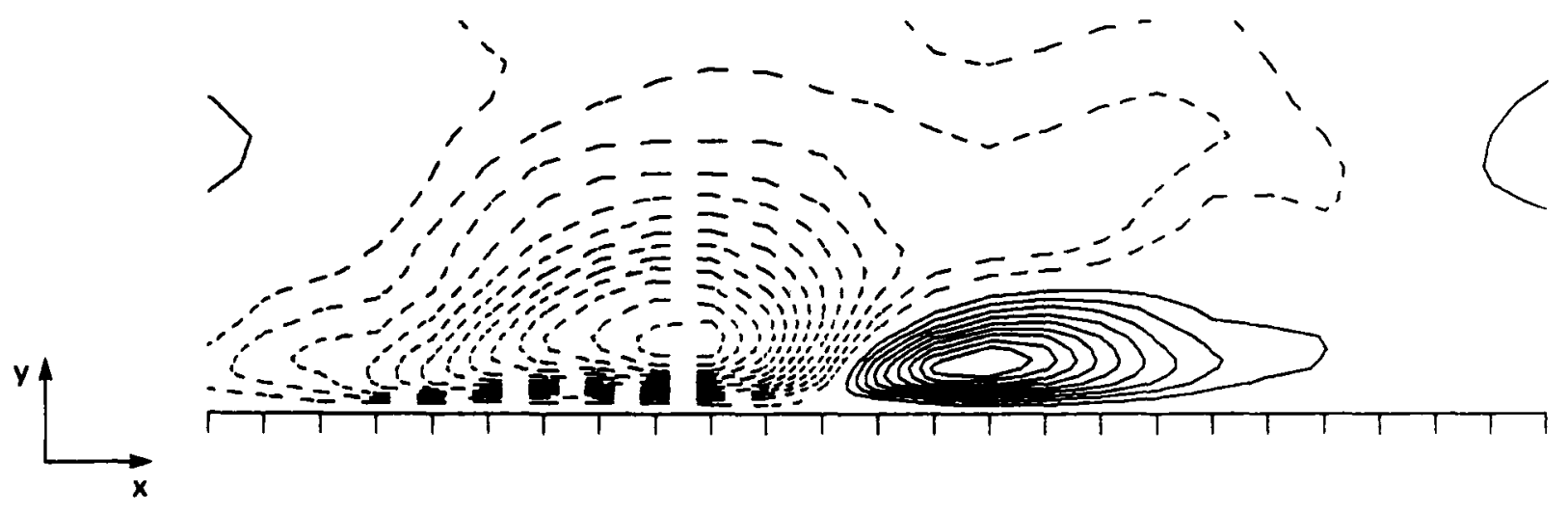

Fig. 10 


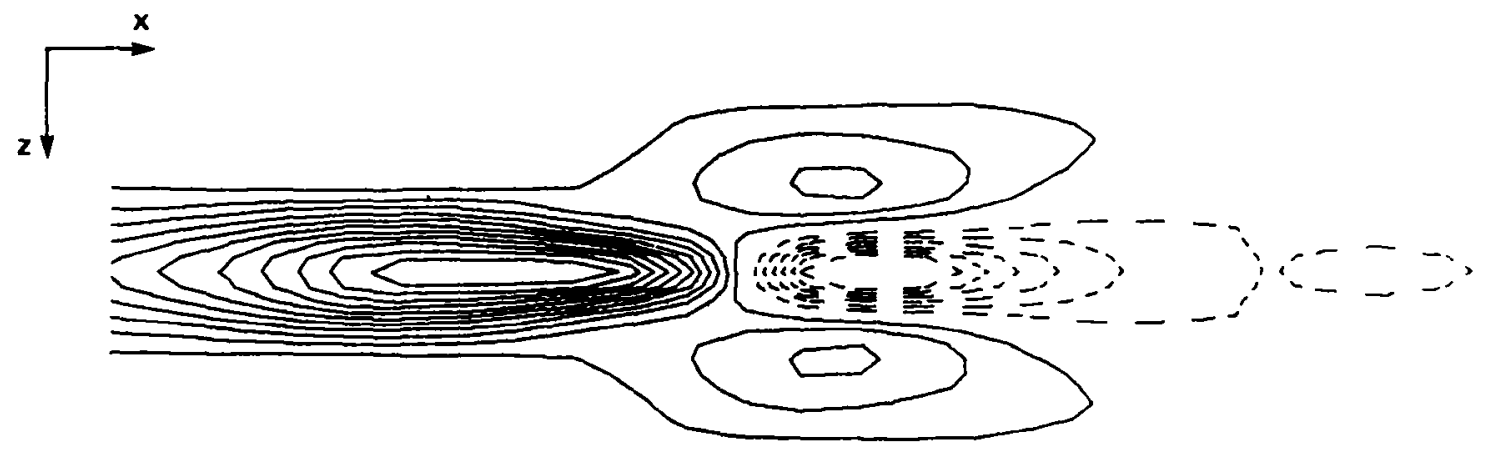

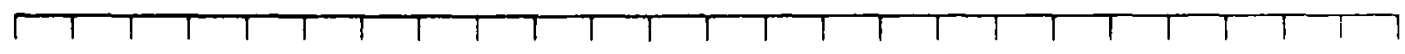

Fig. 11 


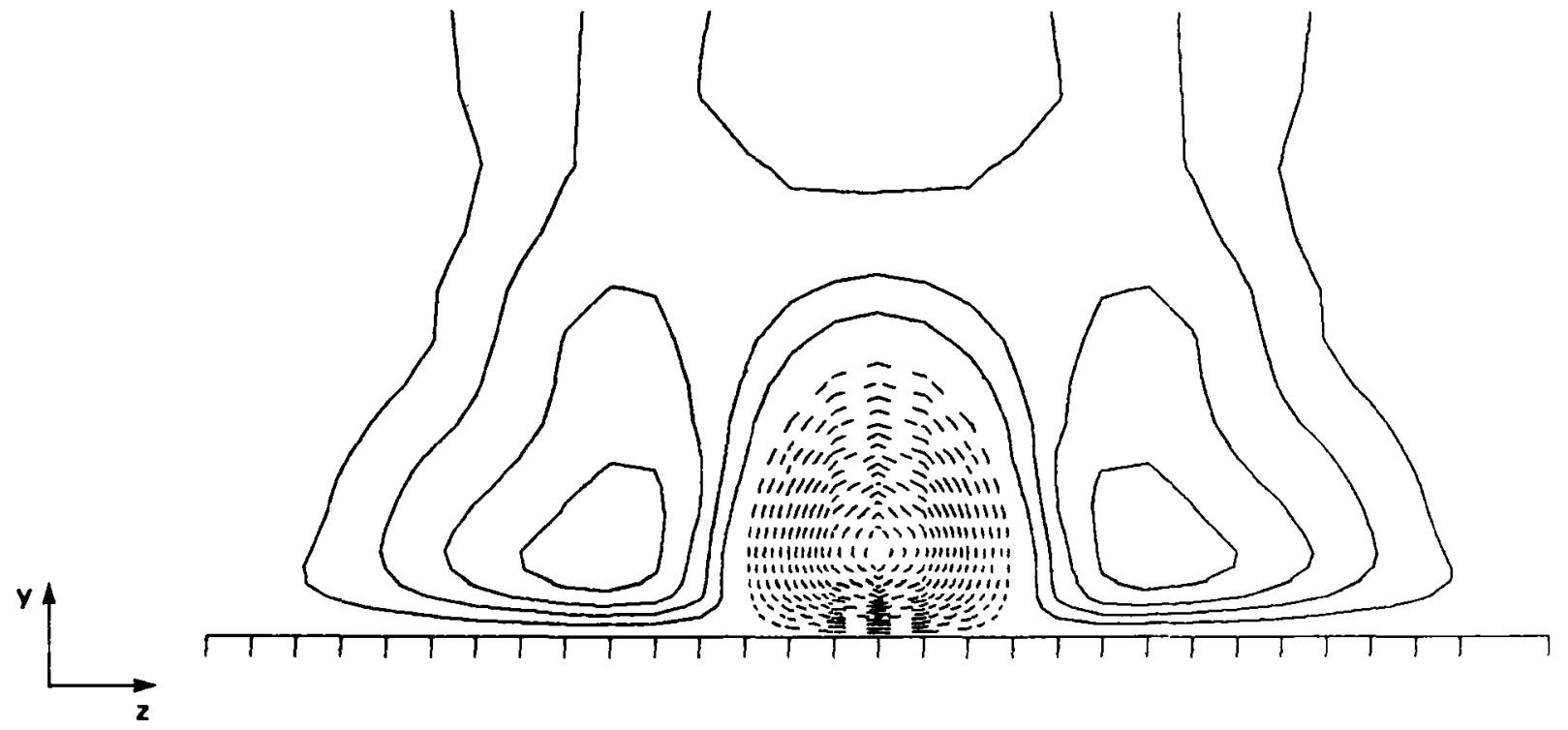

Fig. 12 


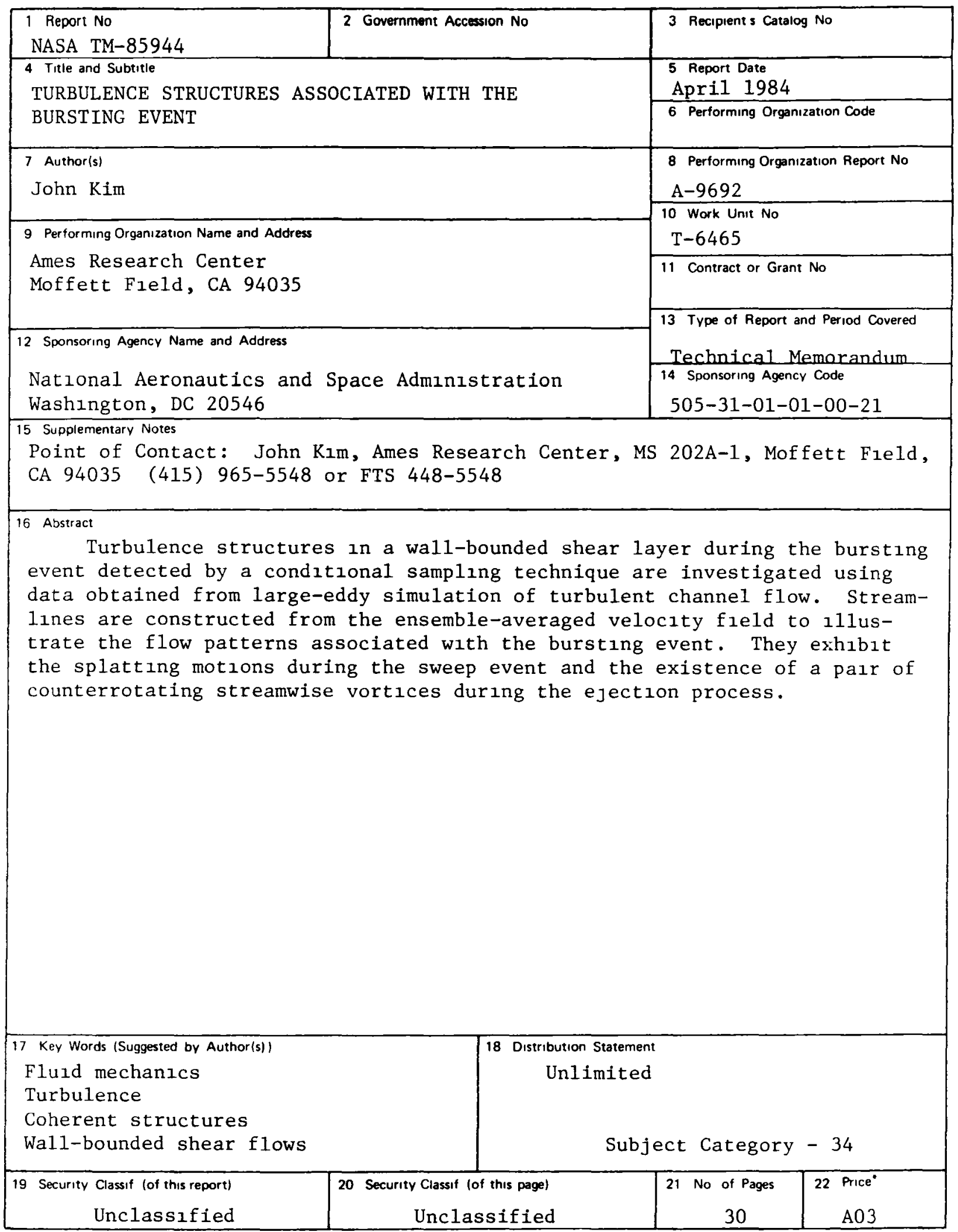

- For sale by the National Terhnical Information Service Springfield, Virginia 22161 
End of Document 